\title{
Nicotinic acetylcholine receptors and cancer (Review)
}

\author{
NINGNING DANG, XIANGUANG MENG and HAIYAN SONG
}

Department of Dermatology, Jinan Central Hospital Affiliated to Shandong University, Jinan, Shandong 250013, P.R. China

Received November 11, 2015; Accepted March 1, 2016

DOI: $10.3892 /$ br. 2016.625

\begin{abstract}
Nicotine, the primary addictive constituent of cigarettes, is believed to contribute to cancer promotion and progression through the activation of nicotinic acetylcholine receptors (nAChRs), which are membrane ligand-gated cation channels. nAChRs activation can be triggered by the neurotransmitter Ach, or certain other biological compounds, such as nicotine. In recent years, genome-wide association studies have indicated that allelic variation in the $\alpha 5-\alpha 3-\beta 4$ nAChR cluster on chromosome $15 q 24-15 q 25.1$ is associated with lung cancer risk. The role of nAChRs in other types of cancer has also been reported. The present review highlights the role of nAChRs in types of human cancer.
\end{abstract}

\section{Contents}

1. Introduction

2. Lung cancer

3. Other cancers

4. Conclusion

\section{Introduction}

Acetylcholine receptors (AChRs), similar to a number of other ligand-activated neurotransmitter receptors in neuronal system, consist of 2 subtypes: Metabotropic muscarinic receptors and ionotropic nicotinic receptors (1). These 2 subtypes can be activated by the endogenous neurotransmitter ACh (1). The first subtype, the metabotropic muscarinic receptors, is $\mathrm{G}$ protein-coupled seven-transmembrane proteins, which directly alter the cellular homeostasis of phospholipase C, inositol-3-phosphate, cyclic adenosine monophosphate and free calcium. Activation of metabotropic AChRs is relatively slow (from msec to sec). The other AChR subtype

Correspondence to: Dr Ningning Dang, Department of Dermatology, Jinan Central Hospital Affiliated to Shandong University, 105 Jiefang Road, Jinan, Shandong 250013, P.R. China E-mail: ningningdangxj@sina.com

Key words: nicotinic acetylcholine receptor, cancer, tobacco is the fast ionotropic cationic nicotinic AChRs (nAChRs). These ion channels are sensitive to activation by acetylcholine and nicotine, and their activation is extremely fast (msec to sub-msec) (1). nAChRs consist of 5 subunits, comprising $10 \alpha$ subunits (from $\alpha 1$ to $\alpha 10$ ), $4 \beta$ subunits (from $\beta 1$ to $\beta 4$ ), $1 \delta$, and $1 \varepsilon$ or $\gamma$ subunit. The receptors can form homo- or hetero-pentamers, and enclose a central ion channel. The $\mathrm{nAChR}$ subunit composition also has a role in regulating the function of nAChRs (1-3). All the nAChRs show permeability to various cations, such as $\mathrm{Na}^{+}, \mathrm{Ca}^{2+}$ and $\mathrm{K}^{+}$, with $\alpha 7 \mathrm{nAChR}$ showing the highest permeability for $\mathrm{Ca}^{2+}$. As well as channel activity, a number of other intracellular events and various downstream signaling pathways can also be regulated by nAChRs, such as $\mathrm{Ca}^{2+} /$ calmodulin, mitogen-activated protein kinase (MAPK), protein kinase $\mathrm{C}$ and vascular endothelial growth factor (VEGF) (4-6). Different $\mathrm{nAChR}$ subtypes also have roles in control distinct physiological processes, such as maintenance, metabolic tone and control of carcinogenesis.

$\mathrm{nAChR}$ genes are expressed not only in neuronal systems, but also in numerous non-neuronal tissues cells such as skin, pancreas and lung, suggesting that nAChRs may have roles in other biological processes in addition to synaptic transmission (7). In fact, nAChRs have been found not only to perform their classic function at neuromuscular junctions, but also to function in the regulation of cellular processes such as cell proliferation (7) and cell death $(1,3,8)$. Decreased survival rates in cancer are believed to be affected by the nAChR pathway activation, influencing tumor cell proliferation, apoptosis $(3,8)$, proinvasive and angiogenic phenotypes (9) and epithelial-mesenchymal transition (EMT). This review summarizes the current evidence of the role of $\mathrm{nAChRs}$ in types of human cancer.

\section{Lung cancer}

Tobacco smoking is known to be the major cause of lung cancer worldwide (10). Numerous large genome-wide association studies have found an association between single-nucleotide polymorphism (SNP) variation at 15q24-15q25.1 and susceptibility to lung cancer (11-18). There are three nicotine acetylcholine receptor (CHRNA) genes at this locus. Studies from the International Agency for Research on Cancer (Lyon, France), the MD Anderson Cancer (Houston, TX, USA), and deCODE Genetics (Reykjavik, Iceland) have shown that there is a nearly $14 \%$ increase in lung cancer susceptibility associated with $\mathrm{nAChR}$ cluster variations, regardless of 
smoking status (12). In addition, a non-synonymous variant, rs16969968, in CHRNA5, which results in an amino acid substitution (D398N) in the second intracellular loop of the protein, can increase lung cancer risk $>30 \%$ (12). In the CHRNA3/CHRNB4 intergenic region, the SNP rs8023462 can interfere with $C H R N A 3 / C H R N B 4$ gene expression by interacting with GATA transcription factors (19). Overexpression of CHRNA3 by ectopic expression was shown to induce apoptosis (20). Knockdown of CHRNA3 by short hairpin RNA (shRNA) in lung cancer cells abolished the response of the cells to apoptosis-inducing agents, suggesting the importance of this gene in human cancer (20). CHRNA3 knockdown may result in overexpression of $C H R N A 7$ and CHRNA5 (20), while abnormal CHRNB4 methylation was found to be insufficient to induce significant silencing of the gene, and could not downregulate gene expression. One study in 28 squamous cell carcinomas (SCCs) of the lung showed increased levels of CHRNA5 and CHRNB3 transcripts, together with higher ACh levels, which is associated with increased levels of choline acetyltransferase transcripts and decreased levels of cholinesterase transcripts. Incubation of the H520 SCC cell line with nicotine increased ACh secretion, expression of $\mathrm{nAChRs}(\alpha 7$ and $\beta 4$ ), and activity of those expressed nAChRs. Darifenacin, an M3 mAChR-selective antagonist, was able to abolish the proliferative effects of nicotine and $\mathrm{ACh}$ on lung cancer growth by downregulating the activation of MAPK (21). Human non-small cell lung cancer (NSCLC) tissues and cancer cells were shown to express $\alpha 7-n A C h R(22)$. Nicotine can cause $\mathrm{Ca}^{2+}$ influx into lung cancer cells by binding to $\alpha 7 \mathrm{nAChR}$ and triggering membrane depolarization, which activates voltage-gated $\mathrm{Ca}^{2+}$ channels and subsequently activates the MAPK pathway, which may result in increased expression of the B-cell lymphoma-2 protein and downregulation of apoptosis (23). Subsequently, the MAPK pathway activates the transcription factor nuclear factor- $\kappa \mathrm{B}(\mathrm{NF}-\kappa \mathrm{B})$ and promotes cancer cell proliferation. Expression of $\alpha 7-\mathrm{nAChR}$ is also associated with activation of the Rb-Raf-1/phospho-extracellular signal-regulated kinase (ERK)/phospho-p90RSK pathway. In certain cases, $\alpha 7-n A C h R$ antagonists were able to inhibit proliferation of human NSCLC cells via mitochondria-associated apoptosis (22). Expression of the $\beta 2$ and $\beta 4 \mathrm{nAChR}$ subunits was also been found in all adenocarcinoma $(\mathrm{AC})$ and SCC tissue samples; in ACs, all $\alpha 5, \alpha 7, \beta 2$ and $\beta 4 \mathrm{nAChR}$ subunits were detected in glandular structures, while in SCCs, the $\alpha 5, \beta 2$ and $\beta 4$ subunits were mainly expressed in tumor cells at invasive fronts (24). $\alpha 7 \mathrm{nAChR}$ inhibited cell proliferation in well-differentiated NSCLC cells, but promoted cell proliferation by mediating the pro-proliferative activity of nicotine in poorly differentiated NSCLC cells (24). The $\alpha 7 \mathrm{nAChR}$ and heteromeric $\alpha 5^{*} \beta 2^{*} \beta 4^{*} \mathrm{nAChRs}$ are involved in tumor progression by stimulating invasion and regulating proliferation (24). Li et al (25) reported that nicotine can promote tumor growth and cause resistance to erlotinib in the PC9 xenograft model by activating the $\alpha 1 \mathrm{nAChR}$ and epidermal growth factor (EGFR) pathways. In A549 cells, use of shRNA or the selective antagonist methoctramine to block M2 mAChR (M2R) signaling resulted in inhibition of tumor cell proliferation in vitro and in vivo. Blocking of M2R signaling decreased MAPK and AKT phosphorylation.
Further studies indicated that M2R signaling also promotes EMT in vitro and in vivo (26). Chernyavsky et al (27) reported that cell membrane $(\mathrm{cm})-\mathrm{nAChRs}$ could promote growth of lung cancer cells, and could also promote growth factor signaling $[\alpha 7 \mathrm{~cm}-\mathrm{nAChR}$ synergizes with EGF, $\alpha 3$ synergizes with VEGF, $\alpha 4$ synergizes with insulin-like growth factor I (IGF-I) and VEGF, and $\alpha 9$ synergizes with EGF, IGF-I and VEGF]; and simultaneous activation of cm- and mitochondrial-nAChRs produces a combination of growth-promoting and anti-apoptotic signals. Activation of M3R by ACh was also found to promote cell proliferation, invasion and migration of lung cancer cells by activating the EGFR/phosphoinositide-3-kinase (PI3K)/AKT pathway and interleukin-8 (28). Recently, it was reported that cyclooxygenase-2-derived prostaglandin E2 increased $\alpha 7 \mathrm{nAChR}$ expression in NSCLC cells, and this effect was regulated by Jun kinase, PI3K, and protein kinase A signals (29). This finding shows a novel link between prostanoids and cholinergic signaling (29).

\section{Other cancers}

Tobacco smoking is also a risk factor for pancreatic cancer. Studies have shown that $\mathrm{nAChR}$ activation can enhance pancreatic tumor-promoting events, and that multiple pathways are involved (30). Nicotine treatment causes a significant reduction in expression of GATA6 and Mist1, both of which are regulators of acinar cell differentiation. Nicotine treatment can not only induce de-differentiation of acinar cells, but can also increase pancreatic progenitor cell activity, by increasing expression of the stem cell genes Sox 9 and $A L D H$ and enhancing cancer stem cell populations. All the effects of nicotine occur through activation of $\alpha 7 \mathrm{nAchR}$, followed by activation of the AKT and MAPK signaling pathways (30). As in the nervous system, nAChRs have roles in regulating the synthesis and release of catecholamines in normal pancreatic ductal cells and in pancreatic cancer cells. Nicotine was shown to induce catecholamine secretion, which was dependent on the $\alpha 3, \alpha 5$ and $\alpha 7 \mathrm{nAChR}$ subunits (31-33). Additional studies also found that in pancreatic cancer cells, nicotine activated ERK1/2, a well-known proliferation and survival-related signaling pathway (34-36).

Nicotine also inhibits $\gamma$-aminobutyric acid (GABA) synthesis and secretion in normal pancreatic cells and cancer cells in a time-dependent manner. GABA is able to inhibit pancreatic tumor growth in vivo and in vitro, which can be facilitated through the $\alpha 4 \mathrm{nAChR}$ subunit $(31,33,37)$. In addition to its proliferative effects, nicotine promotes migration and invasion of pancreatic cancer cells by upregulating the mucin MUC4 in the CD18/HPAF pancreatic cancer cell line (38). The nicotine-induced increase in MUC4 expression is dose-dependent, acting through $\alpha 7 \mathrm{nAChR}$ activation and subsequently activation of Janus kinase 2, signal transducer and activator of transcription 3 (STAT3), and ERK1/2 (38). Nicotine treatment also enhances the association of the MUC4 promoter with the transcription factors E2F1 and STAT1 (39).

Through induction of osteopontin (OPN) synthesis and secretion, nicotine can also promote cell proliferation and metastasis in pancreatic cancer cell lines. Studies on pancreatic cancer cell lines showed that treatment with nicotine 
resulted in increased proliferation and concomitant OPN gene promoter activation, mRNA expression and protein secretion (40). This effect occurred via $\mathrm{nAChR}$ receptor activation, with subsequent phosphorylation of ERK1/2 (40). It has also been found that nicotine-mediated migration, invasion and metastasis of pancreatic cancer cells is dependent on OPN, through inducing matrix metalloproteinase-9 and VEGF (41).

In gastric cancer, nicotine and nicotine-derived nitrosamine ketone (NNK) were found to enhance AGS cell proliferation significantly through $\alpha 7 \mathrm{nAChR}$ and $\beta$-adrenergic receptors. Nicotine promotes cell proliferation, which is dependent on Erk1/2 activation, while NNK-induced cell growth is dependent on p38 MAPK. In addition, nicotine and NNK mediates cyclooxygenase- 2 induction to modulate cell cycle regulatory proteins, and contributes to cancer development. A selective cyclooxygenase-2 inhibitor, SC-236, was shown to block nicotine/NNK-induced cell proliferation (42). An in vitro study on the AGS gastric cancer cell line reported that when $\alpha 7 \mathrm{nAChR}$ was knocked down by siRNA, the cells were more resistant to 5-fluorouracil treatment (43).

ACh receptors are also expressed in human mesothelioma and normal mesothelial cells. Nicotine stimulation prompts cell growth through activation of nicotinic cholinergic receptors. Activation of $\alpha 7 \mathrm{nAChR}$ can cause $\mathrm{Ca}^{2+}$ influx into cells, which subsequently activates voltage-gated $\mathrm{Ca}^{2+}$ channels, which in turn activate the MAPK pathway. Subsequently, MAPK promotes cancer cell proliferation through activating transcription factor NF- $\mathrm{NB}(4)$.

In human mammary epithelial cells, non-malignant MCF10A and malignant MCF7 breast cells were shown to express the $\alpha 3, \alpha 5, \alpha 7, \alpha 9, \alpha 10, \beta 1, \beta 2, \gamma, \delta$ and $\varepsilon$ nAChR subunits and the M1, M3, M4 and M5 muscarinic receptor subtypes. The malignancy was associated with expression of the $\alpha 1, \alpha 4$ and $\beta 4 \mathrm{nAChR}$ subunits and the M2 subtype. Malignant transformation of basal epithelial cells was also associated with overexpression of $\alpha 7$ - and $\alpha 9$-made nAChRs. NNK upregulated ERK1/2 phosphorylation, stimulated expression of the gene encoding the tumor promoter hepatocyte growth factor, downregulated expression of the tumor suppressor gene $C D K N 2 A$ and induced tumorigenic transformation of MCF10A cells (44).

\section{Conclusion}

Taken together, the obtained results provide new insight into the molecular mechanisms of nAChR-mediated oncogenic effects on types of human cancer. It is clear that nAChRs has significant roles in the pathogenesis of cancers. Further analyses of nAChRs may contribute to clinical applications in the future. More in vivo studies are required to confirm their oncogenic effects.

\section{References}

1. Albuquerque EX, Pereira EF, Alkondon M and Rogers SW: Mammalian nicotinic acetylcholine receptors: From structure to function. Physiol Rev 89: 73-120, 2009.

2. Niu XM and Lu S: Acetylcholine receptor pathway in lung cancer: New twists to an old story. World J Clin Oncol 5: 667-676, 2014.

3. Schuller HM: Is cancer triggered by altered signalling of nicotinic acetylcholine receptors? Nat Rev Cancer 9: 195-205, 2009.
4. Trombino S, Cesario A, Margaritora S, Granone P, Motta G, Falugi C and Russo P: Alpha7-nicotinic acetylcholine receptors affect growth regulation of human mesothelioma cells: Role of mitogen-activated protein kinase pathway. Cancer Res 64: $135-145,2004$.

5. Arredondo J, Chernyavsky AI, Jolkovsky DL, Pinkerton KE and Grando SA: Receptor-mediated tobacco toxicity: Cooperation of the Ras/Raf-1/MEK1/ERK and JAK-2/STAT-3 pathways downstream of alpha7 nicotinic receptor in oral keratinocytes. FASEB J 20: 2093-2101, 2006.

6. Nakayama H, Numakawa $T$ and Ikeuchi T: Nicotine-induced phosphorylation of Akt through epidermal growth factor receptor and Src in PC12h cells. J Neurochem 83: 1372-1379, 2002.

7. Bierut LJ: Nicotine dependence and genetic variation in the nicotinic receptors. Drug Alcohol Depend 104 (Suppl 1): S64-S69, 2009.

8. Catassi A, Servent D, Paleari L, Cesario A and Russo P: Multiple roles of nicotine on cell proliferation and inhibition of apoptosis: Implications on lung carcinogenesis. Mutat Res 659: 221-231, 2008.

9. Ng MK, Wu J, Chang E, Wang BY, Katzenberg-Clark R, Ishii-Watabe A and Cooke JP: A central role for nicotinic cholinergic regulation of growth factor-induced endothelial cell migration. Arterioscler Thromb Vasc Biol 27: 106-112, 2007.

10. Beasley MB, Brambilla E and Travis WD: The 2004 World Health Organization classification of lung tumors. Semin Roentgenol 40: 90-97, 2005.

11. Amos CI, Wu X, Broderick P, Gorlov IP, Gu J, Eisen T, Dong Q, Zhang Q, Gu X, Vijayakrishnan J, et al: Genome-wide association scan of tag SNPs identifies a susceptibility locus for lung cancer at 15q25.1. Nat Genet 40: 616-622, 2008.

12. Hung RJ, McKay JD, Gaborieau V, Boffetta P, Hashibe M, Zaridze D, Mukeria A, Szeszenia-Dabrowska N, Lissowska J, Rudnai $\mathrm{P}$, et al: A susceptibility locus for lung cancer maps to nicotinic acetylcholine receptor subunit genes on $15 \mathrm{q} 25$. Nature 452: 633-637, 2008.

13. Thorgeirsson TE, Geller F, Sulem P, Rafnar T, Wiste A, Magnusson KP, Manolescu A, Thorleifsson G, Stefansson H, Ingason A, et al: A variant associated with nicotine dependence, lung cancer and peripheral arterial disease. Nature 452: 638-642, 2008.

14. McKay JD, Hung RJ, Gaborieau V, Boffetta P, Chabrier A, Byrnes G, Zaridze D, Mukeria A, Szeszenia-Dabrowska N, Lissowska J, et al; EPIC Study: Lung cancer susceptibility locus at 5p15.33. Nat Genet 40: 1404-1406, 2008.

15. Wang Y, Broderick P, Webb E, Wu X, Vijayakrishnan J, Matakidou A, Qureshi M, Dong Q, Gu X, Chen WV, et al: Common 5p15.33 and 6p21.33 variants influence lung cancer risk. Nat Genet 40: 1407-1409, 2008.

16. Broderick P, Wang Y, Vijayakrishnan J, Matakidou A, Spitz MR, Eisen T, Amos CI and Houlston RS: Deciphering the impact of common genetic variation on lung cancer risk: A genome-wide association study. Cancer Res 69: 6633-6641, 2009.

17. Liu P, Vikis HG, Wang D, Lu Y, Wang Y, Schwartz AG, Pinney SM, Yang P, de Andrade M, Petersen GM, et al: Familial aggregation of common sequence variants on 15q24-25.1 in lung cancer. J Natl Cancer Inst 100: 1326-1330, 2008.

18. Landi MT, Chatterjee N, Yu K, Goldin LR, Goldstein AM, Rotunno M, Mirabello L, Jacobs K, Wheeler W, Yeager M, et al: A genome-wide association study of lung cancer identifies a region of chromosome $5 \mathrm{p} 15$ associated with risk for adenocarcinoma. Am J Hum Genet 85: 679-691, 2009.

19. Flora AV, Zambrano CA, Gallego X, Miyamoto JH, Johnson KA, Cowan KA, Stitzel JA and Ehringer MA: Functional characterization of SNPs in CHRNA3/B4 intergenic region associated with drug behaviors. Brain Res 1529: 1-15, 2013.

20. Paliwal A, Vaissière T, Krais A, Cuenin C, Cros MP, Zaridze D, Moukeria A, Boffetta P, Hainaut P, Brennan P, et al: Aberrant DNA methylation links cancer susceptibility locus $15 \mathrm{q} 25.1$ to apoptotic regulation and lung cancer. Cancer Res 70: 2779-2788, 2010.

21. Song P, Sekhon HS, Fu XW, Maier M, Jia Y, Duan J, Proskosil BJ, Gravett C, Lindstrom J, Mark GP, et al: Activated cholinergic signaling provides a target in squamous cell lung carcinoma. Cancer Res 68: 4693-4700, 2008.

22. Paleari L, Catassi A, Ciarlo M, Cavalieri Z, Bruzzo C, Servent D, Cesario A, Chessa L, Cilli M, Piccardi F, et al: Role of alpha7-nicotinic acetylcholine receptor in human non-small cell lung cancer proliferation. Cell Prolif 41: 936-959, 2008. 
23. Heusch WL and Maneckjee R: Signalling pathways involved in nicotine regulation of apoptosis of human lung cancer cells. Carcinogenesis 19: 551-556, 1998.

24. Medjber K, Freidja ML, Grelet S, Lorenzato M, Maouche K, Nawrocki-Raby B, Birembaut P, Polette M and Tournier JM: Role of nicotinic acetylcholine receptors in cell proliferation and tumour invasion in broncho-pulmonary carcinomas. Lung Cancer 87: 258-264, 2015.

25. Li H, Wang S, Takayama K, Harada T, Okamoto I, Iwama E, Fujii A, Ota K, Hidaka N, Kawano Y, et al: Nicotine induces resistance to erlotinib via cross-talk between $\alpha 1 \mathrm{nAChR}$ and EGFR in the non-small cell lung cancer xenograft model. Lung Cancer 88: 1-8, 2015.

26. Zhao Q, Gu X, Zhang C, Lu Q, Chen $\mathrm{H}$ and Xu L: Blocking M2 muscarinic receptor signaling inhibits tumor growth and reverses epithelial-mesenchymal transition (EMT) in non-small cell lung cancer (NSCLC). Cancer Biol Ther 16: 634-643, 2015.

27. Chernyavsky AI, Shchepotin IB, Galitovkiy V and Grando SA Mechanisms of tumor-promoting activities of nicotine in lung cancer: Synergistic effects of cell membrane and mitochondrial nicotinic acetylcholine receptors. BMC Cancer 15: 152, 2015.

28. Xu R, Shang C, Zhao J, Han Y, Liu J, Chen K and Shi W: Activation of M3 muscarinic receptor by acetylcholine promotes non-small cell lung cancer cell proliferation and invasion via EGFR/PI3K/AKT pathway. Tumour Biol 36: 4091-4100, 2015.

29. Zhong X, Fan Y, Ritzenthaler JD, Zhang W, Wang K, Zhou Q and Roman J: Novel link between prostaglandin E2 (PGE2) and cholinergic signaling in lung cancer: The role of c-Jun in PGE2-induced $\alpha 7$ nicotinic acetylcholine receptor expression and tumor cell proliferation. Thorac Cancer 6: 488-500, 2015.

30. Schaal C, Padmanabhan J and Chellappan S: The role of nAChR and calcium signaling in pancreatic cancer initiation and progression. Cancers (Basel) 7: 1447-1471, 2015.

31. Al-Wadei MH,Al-Wadei HA and Schuller HM: Effects of chronic nicotine on the autocrine regulation of pancreatic cancer cells and pancreatic duct epithelial cells by stimulatory and inhibitory neurotransmitters. Carcinogenesis 33: 1745-1753, 2012.

32. Al-Wadei MH, Al-Wadei HA and Schuller HM: Pancreatic cancer cells and normal pancreatic duct epithelial cells express an autocrine catecholamine loop that is activated by nicotinic acetylcholine receptors $\alpha 3, \alpha 5$, and $\alpha 7$. Mol Cancer Res 10: 239-249, 2012

33. Al-Wadei HA, Plummer HK III and Schuller HM: Nicotine stimulates pancreatic cancer xenografts by systemic increase in stress neurotransmitters and suppression of the inhibitory neurotransmitter gamma-aminobutyric acid. Carcinogenesis 30 : 506-511, 2009

34. Hermann PC, Sancho P, Cañamero M, Martinelli P, Madriles F, Michl P, Gress T, de Pascual R, Gandia L and Guerra C: Nicotine promotes initiation and progression of KRAS-induced pancreatic cancer via Gata6-dependent dedifferentiation of acinar cells in mice. Gastroenterology 147: 1119-1133.e4, 2014.
35. Bose C, Zhang H, Udupa KB and Chowdhury P: Activation of p-ERK1/2 by nicotine in pancreatic tumor cell line AR42J: Effects on proliferation and secretion. Am J Physiol Gastrointest Liver Physiol 289: G926-G934, 2005.

36. Chowdhury P and Walker A: A cell-based approach to study changes in the pancreas following nicotine exposure in an animal model of injury. Langenbecks Arch Surg 393: 547-555, 2008.

37. Schuller HM, Al-Wadei HA and Majidi M: GABA B receptor is a novel drug target for pancreatic cancer. Cancer 112: 767-778, 2008.

38. Momi N, Ponnusamy MP, Kaur S, Rachagani S, Kunigal SS, Chellappan S, Ouellette MM and Batra SK: Nicotine/cigarette smoke promotes metastasis of pancreatic cancer through a7nAChR-mediated MUC4 upregulation. Oncogene 32: 1384-1395, 2013

39. Kunigal S, Ponnusamy MP, Momi N, Batra SK and Chellappan SP Nicotine, IFN- $\gamma$ and retinoic acid mediated induction of MUC4 in pancreatic cancer requires E2F1 and STAT-1 transcription factors and utilize different signaling cascades. Mol Cancer 11: 24,2012 .

40. Chipitsyna G, Gong Q, Anandanadesan R, Alnajar A, Batra SK, Wittel UA, Cullen DM, Akhter MP, Denhardt DT, Yeo CJ, et al: Induction of osteopontin expression by nicotine and cigarette smoke in the pancreas and pancreatic ductal adenocarcinoma cells. Int J Cancer 125: 276-285, 2009.

41. Lazar M, Sullivan J, Chipitsyna G, Gong Q, Ng CY, Salem AF, Aziz T, Witkiewicz A, Denhardt DT, Yeo CJ, et al: Involvement of osteopontin in the matrix-degrading and proangiogenic changes mediated by nicotine in pancreatic cancer cells. J Gastrointest Surg 14: 1566-1577, 2010.

42. Shin VY, Jin HC, Ng EK, Yu J, Leung WK, Cho CH and Sung JJ: Nicotine and 4-(methylnitrosamino)-1-(3-pyridyl)-1-butanone induce cyclooxygenase-2 activity in human gastric cancer cells: Involvement of nicotinic acetylcholine receptor (nAChR) and beta-adrenergic receptor signaling pathways. Toxicol Appl Pharmacol 233: 254-261, 2008.

43. Chen WY, Huang CY, Cheng WL, Hung CS, Huang MT, Tai CJ, Liu YN, Chen CL and Chang YJ: Alpha 7-nicotinic acetylcholine receptor mediates the sensitivity of gastric cancer cells to 5-fluorouracil. Tumour Biol 36: 9537-9544, 2015.

44. Kalantari-Dehaghi M, Parnell EA, Armand T, Bernard HU and Grando SA: The nicotinic acetylcholine receptor-mediated reciprocal effects of the tobacco nitrosamine NNK and SLURP-1 on human mammary epithelial cells. Int Immunopharmacol 29: 99-104, 2015 